\title{
FOOD LEVEL AND LIFE HISTORY CHARACTERISTICS IN A PHOLCID SPIDER (HOLOCNEMUS PLUCHEI)
}

\author{
By Elizabeth M. JaKob* and Hugh Dingle \\ Department of Entomology, University of California at Davis, \\ Davis, CA 95616
}

\section{INTRODUCTION}

It is often assumed that food intake rate is an important determinant of other behaviors. For example, much of the foraging behavior literature assumes animals attempt to maximize food intake rate (e.g., Stephens and Krebs 1986). When possible one should document effects of food level on important life history characteristics, rather than simply assuming its importance to the animal. As part of a larger study on the evolution of grouping behavior, we report herein the effects of food level on development time, number of instars, and body size in the pholcid spider, Holocnemus pluchei (Scopoli).

Vollrath (1987) reviewed the literature on the relationship between food intake and development time in spiders, and concluded that, in general, growth rate is greatly affected by amount of food. For example, stadia (intermolt intervals) decrease under conditions of high food level in several species (Turnbull 1962, 1965; Vollrath 1987; Miyashita 1968). However, a correlation between food intake and growth rate is not always found: in Tegenaria atrica, food level above a minimum level had no effect on stadia (Browning 1941).

A shorter development time provides obvious evolutionary advantages. In some species, an early-maturing female may be able to lay additional clutches of eggs in a season (Vollrath 1987); many spiders are iteroparous (e.g. Bristowe 1958, Jackson 1978). A fastdeveloping male may have a better chance of finding, guarding, and ultimately mating with an immature female, especially in species that are not continuously breeding (Robinson and Robinson 1973, Lubin 1986); this may be particularly important as several spider

\footnotetext{
*Present address: Department of Zoology, University of Canterbury, Christchurch 1, New Zealand. To whom correspondence should be sent.

*Manuscript received by the editor January 30, 1990.
} 
species are known to exhibit first male sperm precedence (Austad 1984).

Feeding level may also influence the number of instars a spider undergoes before it matures, but here the relationship is not so clearcut. In most reported cases, an increase in food level results in a decreased number of instars (Deevey 1949, Miyashita 1968, Toft 1983, Vollrath 1987) and a concomitant decrease in development time. However, the number of instars may be constant no matter what the feeding regime (Turnbull 1962).

More food often leads to bigger spiders (e.g., Vollrath 1987). Body size of female spiders is, in turn, generally positively correlated with the number or biomass of eggs produced (Wise 1975, 1976, 1979; Kessler 1971, 1973 (cited in Vollrath, 1987); Austin 1984; Peterson 1950; Riechert and Tracy 1975; Eberhard 1979; Killebrew and Ford 1985). In several species, large body size confers a competitive advantage over conspecifics (Christenson and Goist 1979, Riechert 1984, Rubenstein 1987).

In the field, there exists variation in the amount of food available to Holocnemus pluchei spiderlings. Spiderlngs may live alone in webs or may share webs with larger conspecifics. Group-living spiderlings capture less food than do solitary spiderlings (Jakob 1989). The aim of the present study is to document, via a laboratory experiment, the impact of different food levels for this particular species.

\section{Methods AND Materials}

\section{Experimental design}

We reared ten families of spiders at three food levels under controlled conditions. This design enabled us to separate the effects of food level from family effects on life history traits.

\section{Rearing procedures}

Ten females holding clutches of eggs in their chelicerae were captured on the University of California at Davis campus in early August, 1987. The animals were housed in plastic cups in growth chambers until the eggs hatched. Holocnemus spiderlings do not build webs or feed during their first instar post-hatch, so they were allowed to stay in their mothers' webs until their first molt.

After the spiderlings molted, each was transferred with a paintbrush to its own plastic cup, $11 \mathrm{~cm}$ high $\times 8 \mathrm{~cm}$ in diameter. Each 
cup had three $10 \mathrm{~cm}$ bamboo sticks arranged in a tripod for web support, and was covered with plastic wrap secured with a rubber band. Animals were kept in five growth chambers with a 13:11 L:D cycle, at $32^{\circ} \mathrm{C}$ during the light period and $20^{\circ} \mathrm{C}$ during the dark cycle. This temperature and light regime approximated field conditions at the time of collection. Spiders were rotated among chambers on alternate days.

Each family of spiderlings was divided into three groups, corresponding to low, medium, and high food levels. (Spiderlings cannot be sexed and were randomly assigned to food levels.) The low feeding group received one Drosophila every other day, the medium was given one fruit fly daily, and the high group received four fruit flies per day. Ten days after each spiderling's third molt posthatch, feeding rates were doubled to one fruit fly daily, two flies daily, and eight flies daily, respectively. In addition, every spider received one large flour beetle larva (Tribolium confusum) every four days throughout the experiment. (In preliminary trials, spiderlings that received only Drosophila died during their fourth molt.) Ten to fifteen minutes after prey were introduced into webs, the spiders were checked to see if they had indeed successfully captured the prey. If the prey had escaped, more were introduced. Nearly all spiders successfully caught their prey by the second attempt.

As it was sometimes difficult to distinguish penultimate and adult females, females were tested for sexual maturity by allowing them to mate. Mature males were recognized by their characteristic palps.

\section{Measurements}

Each day, spiders were checked for molting, and stadia were noted as a measure of development time. Old exoskeletons were removed from the cups after all family members molted.

After the animals reached sexual maturity, they were measured to the nearest millimeter with an ocular micrometer. Chosen for ease of measurement were: length of the first right tibia, length of the second right tibia, carapace length, carapace width, and abdomen length.

\section{Analysis}

Males and females were compared by combining spiders from all treatments. Differences between the sexes in morphological measurements and number of molts were tested with Mann-Whitney $U$ tests and a chi-square test, respectively. In order to see how closely 
body measurements were correlated for each spider, pairwise Spearman's rank tests were performed between each pair of measurements for each sex.

Analysis of variance was used to clarify the effects of food, gender, and family on development time and body size. The data were leptokurtic, and were transformed with natural logarithms. Three-factor ANOVAs (main effects of food, gender, and family) were performed on the entire data set. Because of significant interaction effects between gender and other factors, probably resulting in part from skewed sex ratios in some families and feeding levels, the sexes were then analyzed separately with two-factor ANOVAs. Food $X$ family interactions were still significant in some cases, so we chose the Type III, or complete least-squares analysis. This ANOVA is useful when interaction effects are significant, as it adjusts the main effects for the interaction effects (Freund and Littell 1981). For each significant ANOVA, Duncan's multiple range tests were performed to determine which means differed significantly. However, follow-up tests such as the Duncan's multiple range test are not as reliable when interaction terms are significant, so Duncan's tests are presented only from ANOVAs without significant interaction terms.

In addition, we investigated the effect of number of instars on early stadia. Two-factor ANOVAs, blocked by family and total number of instars, for Stadia II, II, IV, and V were performed for each sex at each food level.

Nonparametric tests were performed with Statview $512+$ on a Macintosh Plus. Parametric analyses were performed with the Systems Analysis Systems (SAS) statistical package (Version 5) on a mainframe computer at the University of California at Davis.

\section{RESULTS}

\section{Development time}

Both males and females showed a significant decrease in total development time (egg to adult) in response to an increase in food level (two-factor ANOVA; Table 1). Each stadium also showed significant differences across food levels, with the exception of Stadium VI in females. Duncan's multiple range tests for ANOVAs without significant interaction terms indicated that low and high food treatments were significantly different, but that the medium 


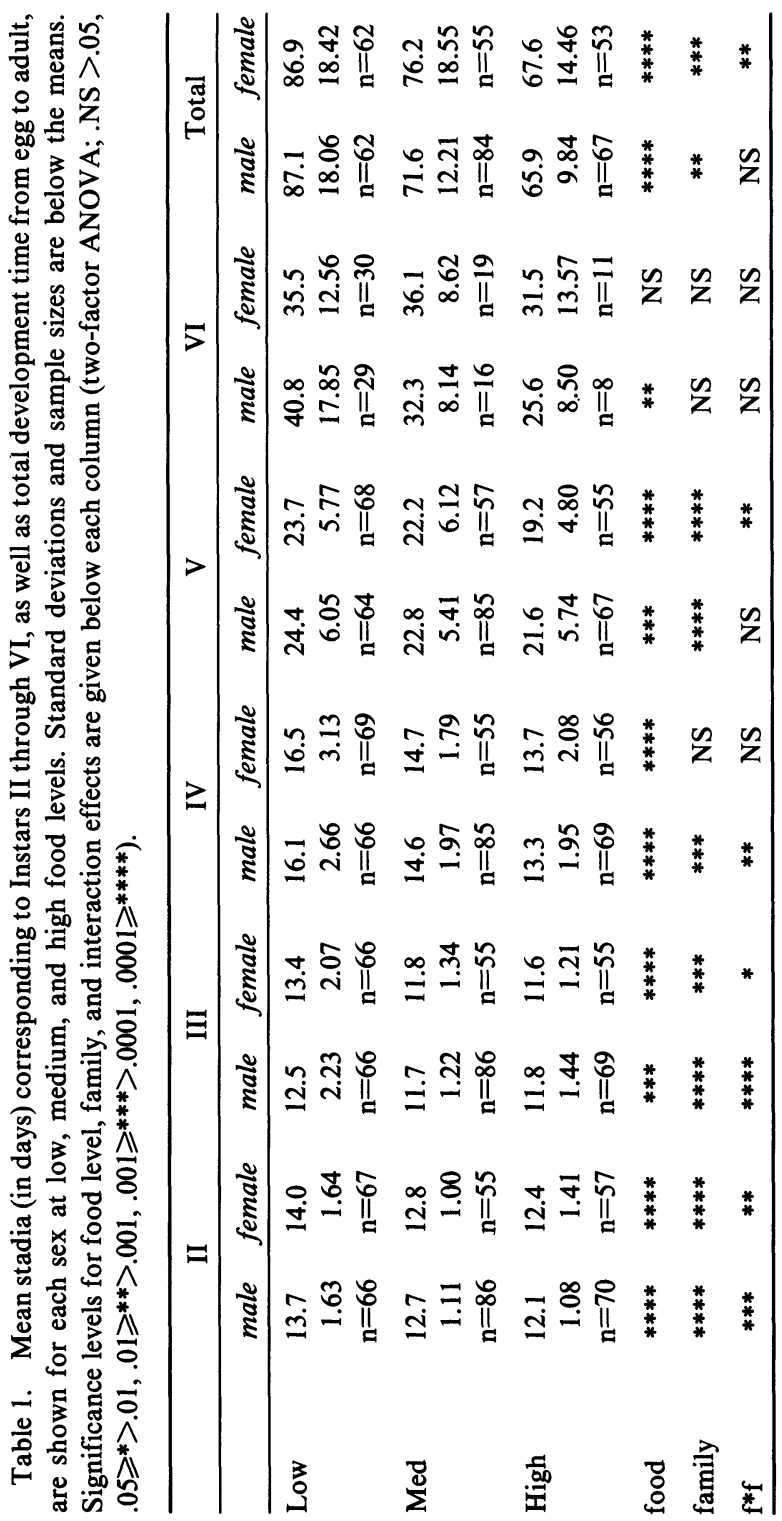


level treatment was indistinguishable from the low and the high. An exception is total development time, for which all three treatments differed significantly. Family effects also significantly influenced development time, particularly in the earlier instars, as did family $X$ food level interaction effects. A three-factor ANOVA (gender, food level, and family) for all spiders together indicated that gender did not significantly affect any stadium; however, gender significantly influenced total development time $(\mathrm{p}<.01)$.

Two-factor ANOVAs to determine the influence of number of instars and family on early stadia showed that number of instars did not affect Stadia II, III, IV, or V for either sex at any food level. That is, the developmental rate during earlier instars of spiders that molt six times is not significantly different from those that molt five times.

\section{Number of instars}

Food level and gender significantly influenced the number of instars. Poorly-fed spiders were more likely to undergo a sixth molt than were well-fed spiders (Figure 1). Only $16 \%$ of high feeding level spiders needed six molts to reach maturity, compared to $24 \%$ of medium and $37 \%$ of low feeding groups $\left(\chi^{2}\right.$ test; $\left.p<.0003\right)$. Females were significantly more likely to undergo a sixth molt than were males $\left(\chi^{2}\right.$ test, $\left.\mathrm{p}<.0002\right)$.

\section{Body size}

In males, food level significantly affected lengths of the first and second tibiae (two-factor ANOVA; Table 2). Duncan's multiple range tests indicated that mean lengths of the first tibiae were significantly different for all three food levels; for the second tibae, means for low and medium treatment grouped together, but significantly differed from the high. Family effects also significantly influenced the length of the first tibiae. Carapace length and width and abdomen length did not significantly change in response to food level; family effects, however, were significant. Family $\times$ food level interaction effects were significant in several cases.

For females, mean morphological measurements were lowest for the low food level and highest for the medium food level treatment. However, treatment effects were significant only for the tibiae measures. Duncan's multiple range test indicates that for the first tibia, the low food treatment is distinguishable from the other treatments, but the medium and high treatments are not significantly different. 


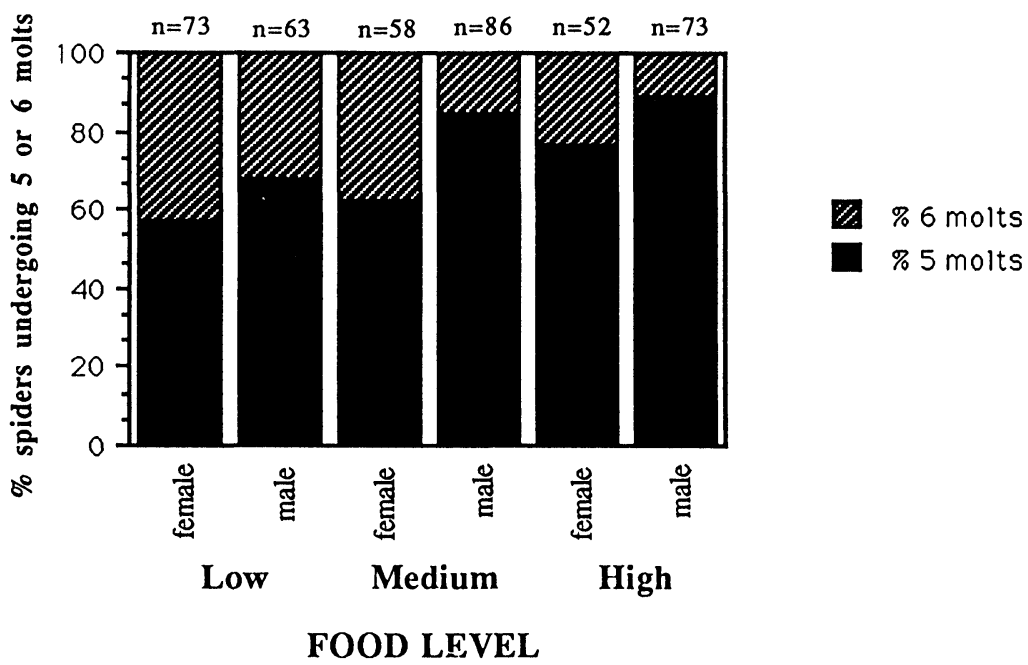

Figure 1. Percent of spiders reaching maturity in five molts and six molts for three food levels.

For the second tibia, the low and medium treatments group together, but both significantly differ from the high treatment.

All females and all males were compared to find general differences between the sexes. Males had significantly longer tibiae than did females, but the males' carapaces and abdomens were significantly smaller (Table 3 ).

Across food levels, females that reached maturity in five molts were significantly smaller on all five measures than were females that matured in six molts (Table 4). The same was true for males.

Pairwise Spearman's rank correlations between each of the five morphological measures were significant, save for the correlation between carapace length and width in males (Table 5). Correlations between abdomen length and measures of heavily sclerotized body parts (cephalothorax and legs) tended to be less strong than correlations between sclerotized parts, though they were still significant at the 0.05 level.

\section{Discussion}

\section{Development time}

Spiders of both sexes reached maturity more quickly with higher food levels; development time from egg to adult was 20 days longer 


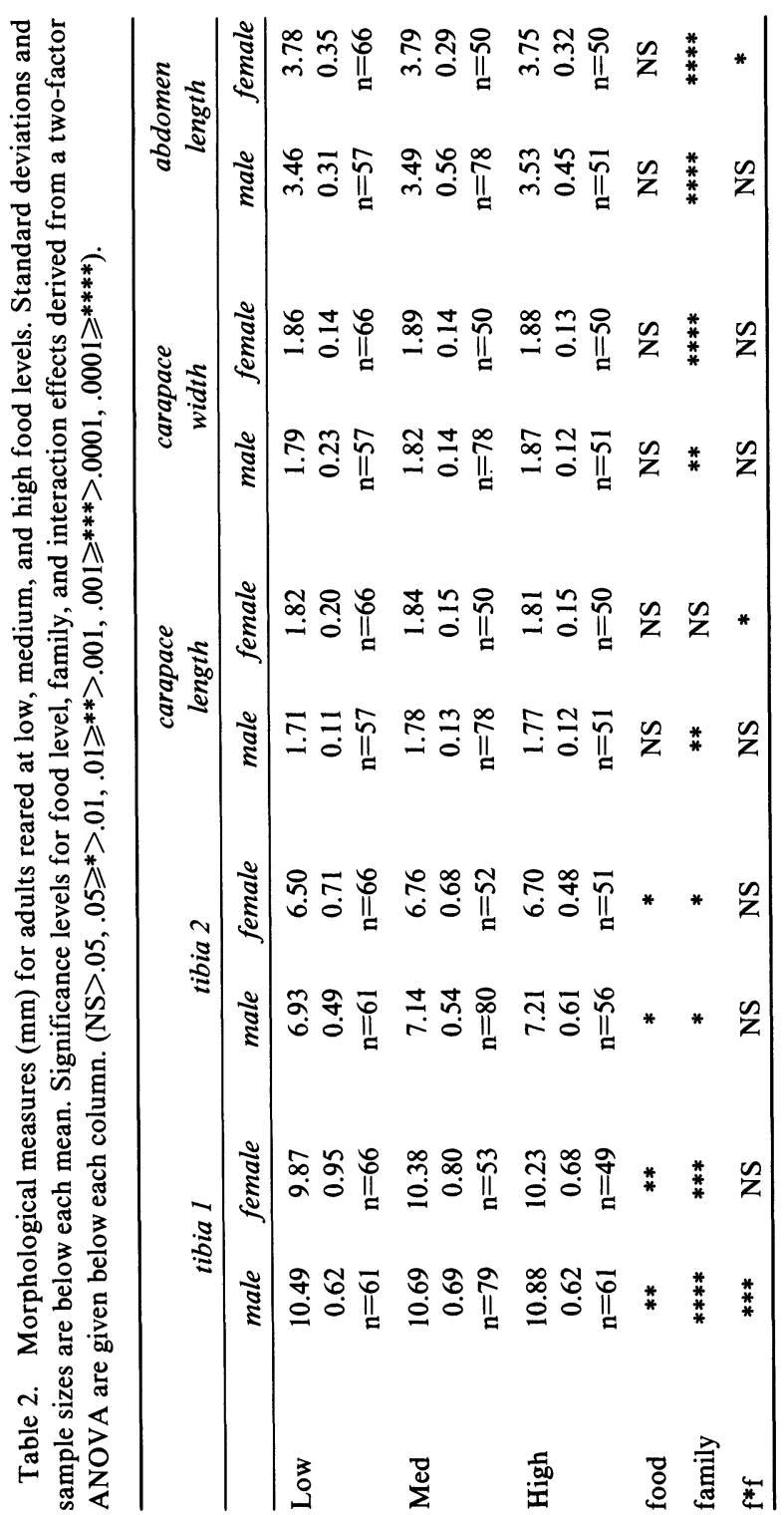


Table 3. A comparison of morphological measurements $(\mathrm{mm})$ of adult males and females (animals from all feeding groups combined). Significance values are derived from Mann-Whitney U tests. Standard errors and sample sizes are given below each mean.

\begin{tabular}{lccc}
\hline & Males & Females & Significance \\
\hline tibia 1 & 10.67 & 10.05 & $\mathrm{p}<.0005$ \\
& .045 & .076 & \\
tibia 2 & $\mathrm{n}=204$ & $\mathrm{n}=172$ & \\
& 7.10 & 6.48 & $\mathrm{p}<.0005$ \\
& .038 & .082 & \\
carapace length & $\mathrm{n}=202$ & $\mathrm{n}=171$ & \\
& 1.76 & 1.82 & $\mathrm{p}<.05$ \\
& .009 & .012 & \\
carapace width & $\mathrm{n}=191$ & $\mathrm{n}=166$ & \\
& 1.83 & 1.93 & $\mathrm{p}<.03$ \\
& .014 & .028 & \\
abdomen length & $\mathrm{n}=191$ & $\mathrm{n}=166$ & \\
& 3.45 & 3.75 & $\mathrm{p}<.0005$ \\
& .035 & .033 & \\
\hline
\end{tabular}

in the low feeding group than the high. Though weather conditions are favorable for these spiders for six months or more of the year in central California, fast development may still confer a reproductive advantage on both sexes. Female Holocnemus may be able to lay multiple clutches within a single season; one marked female was seen carrying a second clutch of eggs within two months after the first had successfully hatched (Jakob, unpublished observation). Similarly, males that mature quickly may increase their opportunities for successful reproduction. Holocnemus populations are not synchronized in their development, and every instar can be found throughout the summer. Receptive females should be present in the population throughout the field season, but they may be scarce. Males should thus gain from maximizing their time as adults, and one way to do this is to develop more quickly. There is no reason to believe that males are extremely short-lived in the field. In the laboratory, males live for at least two to three months past maturity when provided with food and webs (adult males did not build their own webs in the lab during this study). In the field, adult males are 
Table 4. Morphological measurements $(\mathrm{mm})$ of spiders that reached maturity in five molts are compared with those of spiders that matured in six molts. Standard deviations are given in parentheses. Significance levels are derived from MannWhitney $\mathrm{U}$ tests.

\begin{tabular}{|c|c|c|c|}
\hline \multirow[b]{3}{*}{ tibia 1} & \multicolumn{2}{|c|}{ Females } & \multirow[b]{3}{*}{$\mathrm{p}<.00003$} \\
\hline & 5 molts & 6 molts & \\
\hline & $\begin{array}{c}9.88 \quad(.675) \\
n=111\end{array}$ & $\begin{array}{c}10.76 \quad(.864) \\
n=50\end{array}$ & \\
\hline tibia 2 & $\begin{array}{c}6.45 \quad(.491) \\
n=112\end{array}$ & $\begin{array}{c}7.08 \quad(.701) \\
n=50\end{array}$ & $\mathrm{p}<.00003$ \\
\hline carapace length & $\begin{array}{c}1.77 \quad(.120) \\
\mathrm{n}=110\end{array}$ & $\begin{array}{c}1.94 \quad(.197) \\
\mathrm{n}=49\end{array}$ & $\mathrm{p}<.00003$ \\
\hline carapace width & $\begin{array}{c}1.84 \quad(.110) \\
\mathrm{n}=110\end{array}$ & $\begin{array}{c}1.96 \quad(.146) \\
n=49\end{array}$ & $\mathrm{p}<.00003$ \\
\hline \multirow[t]{3}{*}{ abdomen length } & $\mathrm{n}=110$ & $\mathrm{n}=49$ & $\mathrm{p}<.04$ \\
\hline & \multicolumn{2}{|c|}{ Males } & \\
\hline & 5 molts & 6 molts & \\
\hline tibia 1 & $\begin{array}{c}10.56 \quad(.559) \\
\mathrm{n}=149\end{array}$ & $\begin{array}{c}11.12 \quad(.791) \\
\mathrm{n}=47\end{array}$ & $\mathrm{p}<.0003$ \\
\hline tibia 2 & $\begin{array}{c}7.03 \quad(.477) \\
n=145\end{array}$ & $\begin{array}{c}7.34 \quad(.710) \\
n=47\end{array}$ & $\mathrm{p}<.0003$ \\
\hline carapace length & $\begin{array}{c}1.73(.120) \\
n=140\end{array}$ & $\begin{array}{c}1.82 \quad(.135) \\
n=41\end{array}$ & $\mathrm{p}<.0003$ \\
\hline carapace width & $\begin{array}{c}1.80 \quad(.118) \\
n=140\end{array}$ & $\begin{array}{c}1.91 \quad(.270) \\
\mathrm{n}=41\end{array}$ & $\mathrm{p}<.0003$ \\
\hline abdomen length & $\begin{array}{c}3.50 \quad(.478) \\
n=140\end{array}$ & $\begin{array}{c}3.40 \quad(.396) \\
\mathrm{n}=41\end{array}$ & $\mathrm{p}<.05$ \\
\hline
\end{tabular}

often found in females' webs where they aggressively steal food (Jakob, unpublished observations). The lifespan of males seems more likely to be ended by adverse conditions at the end of the season rather than by early senescence; thus, a fast developing male should have more time to search for mates.

\section{Number of molts}

Poorly-fed spiders were more likely to undergo an extra molt than were well-fed spiders, and females were more likely to undergo an extra molt than males (Figure 1). It may be that a spider requires a certain minimum amount of food before it is able to molt to maturity. The sixth instar, when present, was highly variable in length, ranging from 10 days to 85 days. The sixth instar probably 
Table 5. Significance values derived from pairwise Spearman rank correlation coefficients between each of five morphological measures. Males are above the diagonal, females are below.

\begin{tabular}{lccccc}
\hline & tibia 1 & tibia 2 & $\begin{array}{c}\text { carapace } \\
\text { length }\end{array}$ & $\begin{array}{c}\text { carapace } \\
\text { width }\end{array}$ & $\begin{array}{c}\text { abdomen } \\
\text { length }\end{array}$ \\
\hline tibia 1 & - & .00003 & .00003 & .00003 & .0162 \\
tibia 2 & .00003 & - & .00003 & .00003 & .0166 \\
carapace length & .00003 & .00003 & - & .3707 & .00003 \\
carapace width & .00003 & .00003 & .00003 & - & .00011 \\
abdomen length & .0060 & .0495 & .00003 & .00003 & - \\
\hline
\end{tabular}

accounts for the difference in average total development time between the sexes; stadia were generally not different for males and females, but females tended to add another instar.

\section{Body size}

The five measures of body size tended to be highly correlated with one another. However, correlations between abdomen length and tibia size tended to be weaker than other correlations. This is not surprising, as abdomens are distensible and swell during feeding. Though spiders at the same food level had been given the same number of prey, it is likely that individuals varied in the amount they had consumed immediately before measurements were made.

Male spiders given more food had significantly longer tibiae at maturity than spiders given less food. Food level also influenced female tibia length, but the relationship may be more complex than in males. Females raised at a low food level had shorter tibiae than did the spiders reared at an intermediate food level, but tibia lengths of medium and high food level spiders did not differ significantly; in fact, the mean tibia lengths of high food level spiders were slightly shorter than those of medium food level spiders (Table 2). It seems that food level has a nonlinear effect on female tibia length; it would be informative to repeat this experiment with a broader range of food levels in order to clarify this relationship.

Clutch sizes of females were not measured in this experiment. One might expect carapace and abdomen size to be a stronger predictor of potential clutch size than tibia length; however, food levels did not significantly affect these measures. The impact of food levels on clutch size remains unclear without further experiments. 
It is certain that larger Holocnemus spiders hold a competitive advantage: in experiments in which prey were introduced to webs that held more than one spider, the largest spider in the web that detected the prey won the prey about $80 \%$ of the time (Jakob 1989). Spider fights began by web-plucking with first legs extended perpendicular to the body and parallel to the first legs of the opponent, suggesting that the spiders may use leg length to assess the size of opponents. Observations indicate that spiders with longer legs were more likely to win a fight than those with shorter legs, even when the latter was apparently heavier than the former. Because males have longer legs than females (Table 3), they should have a competitive advantage over females, and observations suggest that this is the case.

Spiders that underwent an extra molt were significantly larger at maturity than those that did not. Because of the correlation between size and competitive ability, spiders that undergo a sixth molt should be better competitors as adults than those that only undergo five molts. Since most spiders in our study area live in groups (Jakob 1989), a large adult may be able to regain some losses incurred when it was a spiderling by stealing food from conspecifics. It is difficult to predict whether the benefits of increased competitive ability can balance the costs of increased development time; this would be an interesting direction for future research.

General considerations: possible genetic influences

The strong family effects that influence both development and body size are worth comment. Family effects may indicate the presence of a genetic component in determining life history traits; this would not be surprising in view of the wide range of literature documenting such effects in arthropods (e.g., Dingle et al. 1988). A possible mechanism for differential growth under the same conditions might be a genetically determined ability to more efficiently convert food to biomass (e.g., Araneus diadematus [Ramousse 1973]). However, the full-sib design of this experiment does not allow for the separation of maternal effects from genetic effects. For example, the condition of the mother may influence egg size, which in turn may have lasting impact on spiderling development. An experiment designed to separate maternal and genetic components of variation in life history traits would be most interesting, particularly in light of electrophoretic data suggesting that genetic variation across California populations is quite low (Porter and Jakob 1990). 
Implications for behavioral work

The food level available to Holocnemus spiderlings has great potential for influencing their adult behavior and reproductive success. Food is often limiting for spiders in the field (Anderson 1974, Wise 1975). Holocnemus adults in natural conditions vary greatly in size; the range of morphological measurements for field-caught adults is greater than that found in this experiment (Jakob 1989). This indicates that food level intake during development is probably variable for different individuals. Because of the implications food level has for increasing the chance of reproductive success, we predict that spiderlings should behave in order to increase their level of food intake, all other things being equal.

\section{SUMMARY}

The effects of food level on development and adult body size were investigated for the pholcid spider Holocnemus pluchei. Increased food level significantly decreased development time from egg to adult. Spiders fed less food had longer stadia and were more likely to undergo an additional instar than spiders fed more food. Well-fed spiders of both sexes tended to be larger than poorly-fed spiders, though the relationship between food level and body size was less clearcut for females than for males. Adult female spiders that underwent an extra molt were significantly larger than those that did not. Because Holocnemus spiders often live in groups, and large spiders often steal food from smaller conspecifics, adult females reared under low food conditions that underwent an extra molt may have a competitive edge over their fast-growing, well-fed counterparts.

\section{ACKNOWLEDGEMENTS}

M. Bernadett, C. Oi, K. Evens, R. Snyder, and A. Porter provided excellent technical assistance in rearing spiders. $K$. Laing assisted with SAS. C. Toft loaned us her dissecting scope. T. Mousseau, K. Laing, S. McWilliams, and the UCD Statistics Laboratory generously gave statistical advice. The comments of P. Eason, P. Ward, J. Stamps, and A. Porter greatly improved the manuscript. This work was supported by a UCD Jastro-Shields Research Award to EMJ. 


\section{Literature Cited}

ANDERSON, J.

1974. Responses to starvation in the spiders Lycosa lenta Hentz and Filistata hibernalis (Hentz). Ecology 55: 576-585.

Austad, S.

1984. Evolution of sperm priority patterns in spiders. In: Smith, R. L. (ed.) Sperm competition and the evolution of animal mating systems. Academic Press, New York.

Austin, A.

1984. Life history of Clubiona robusta L. Koch and related species (Araneae, Clubionidae) in South Australia. J. Arachnol. 12: 87-104.

BRISTOWE, W. S.

1958. The World of Spiders. Collins, London.

BrowNING, H.

1941. The relation of instar length to the external and internal environment in Tegenaria atrica (Arachnida). Proc. Zool. Soc. London Ser. A 111: 303-317.

Christenson, T. E. And Goist, K. C.

1979. Costs and benefits of male-male competition in the orb-weaving spider Nephila clavipes. Behav. Ecol. Sociobiol. 5: 87-92.

DeEveY, G.

1949. The developmental history of Latrodectus mactans (Fabr.) at different rates of feeding. Am. Midl. Nat. 42: 189-219.

Dingle, H., Evans, K., and Palmer, J.

1988. Responses to selection among life-history traits in a nonmigratory population of milkweed bugs (Oncopeltus fasciatus). Evolution 42(1): 79-92.

EBERHARD, W.

1979. Rate of egg production by tropical spiders in the field. Biotropica 11: 292-300.

FReUND, R. J. AND LitTell, R. C.

1981. SAS for Linear Models, Cary, N. C.: SAS Institute Inc.

JACKSON, R.

1978. Life history of Phidippus johnsoni (Araneae, Salticidae). J. Arachnol. 6: 1-29.

JAKOB, E. M.

1989. Costs and Benefits of Group Living in a Pholcid Spider (Holocnemus pluchei). PhD. dissertation, University of California at Davis, Davis, CA.

Kessler, A.

1971. Relation between egg production and food consumption in species of the genus Pardosa (Lycosidae, Araneae) under experimental conditions of food-abundance and food-shortage. Oecologia 8: 93-109.

1973. A comparative study of the production of eggs of eight Pardosa species in the field. Tijdschr. Entomol. 116: 23-41. 
Killebrew, D. AND Ford, N.

1985. Reproductive tactics and female body size in the green lynx spider, Peucetia viridans (Araneae, Oxyopidae). J. Arachnol. 13: 375-382.

LuBin, Y.

1986. Courtship and alternative mating tactics in a social spider. J. Arachnol. 14: 239-257.

MiYashita, K.

1968. Growth and development of Lycosa T-insignata Boes et Str. (Araneae:Lycosidae) under different feeding conditions. Appl. Ent. Zool. 3(2): 81-88.

Peterson, B.

1950. The relationship between size of mothers and numbers of eggs and young in some spiders and its significance for evolution of size. Experientia 6: 96-98.

PorTer, A. AND JAKOB, E.

1990. Allozyme variation in the introduced spider Holocnemus pluchei (Araneae: Pholcidae) in California. J. Arachnol., in press.

RAMOUSSE, $\mathbf{R}$.

1973. Body, web-building and feeding characteristics of males of the spider Araneus diadematus (Araneae: Araneidae). Psyche 80: 22-47.

RIECHERT, S.

1984. Games spiders play. III: Cues underlying context-associated changes in agonistic behavior. Anim. Behav. 32: 1-15.

Riechert, S. AND Tracy, C.

1975. Thermal balance and prey availability: bases for a model relating web site characteristics to spider reproductive success. Ecology 56: 265-284.

Robinson, M. AND RoBinson, B.

1973. Ecology and behavior of the giant wood spider Nephila maculata (Fabricius) in New Guinea. Smithson. Contrib. Zool. 149: 1-76.

Rubenstein, D. I.

1987. Alternative reproductive tactics in the spider Meta segmentata. Behav. Ecol. Sociobiol. 20: 229-237.

STEPhENS, D. AND J. KREBS

1986. Foraging Theory. Princeton University Press, Princeton, New Jersey.

TOFT, S.

1983. Life cycles of Meta segmentata (Clerck, 1757) and Meta mengei (Blackwall, 1869) in western Europe (Arachnida:Araneae:Tetragnathidae). Verh. Naturwiss. Ver. Hamb. NS 26: 265-276.

Turnbull, A.

1962. Quantitative studies of the food of Linyphia triangularis Clerck (Araneae:Linyphiidae). Can. Entomol. 94: 1233-1249.

1965. Effects of prey abundance on the development of the spider Agelenopsis potteri. Can. Entomol. 97: 141-147. 
VOLLRATh, F.

1987. Growth, foraging and reproductive success. In: Nentwig, Wolfgang (ed.) Ecophysiology of Spiders. Springer-Verlag, Berlin.

WISE, D.

1975. Food limitation of the spider Linyphia marginata: Experimental field studies. Ecology 56: 637-646.

1976. Variable rates of maturation of the spider, Neriene radiata (Linyphia marginata). Am. Midl. Nat. 96: 66-75.

1979. Effects of an experimental increase in prey abundance upon the reproductive rates of two orb-weaving spider species (Araneae:Araneidae). Oecologia 41: 289-300. 

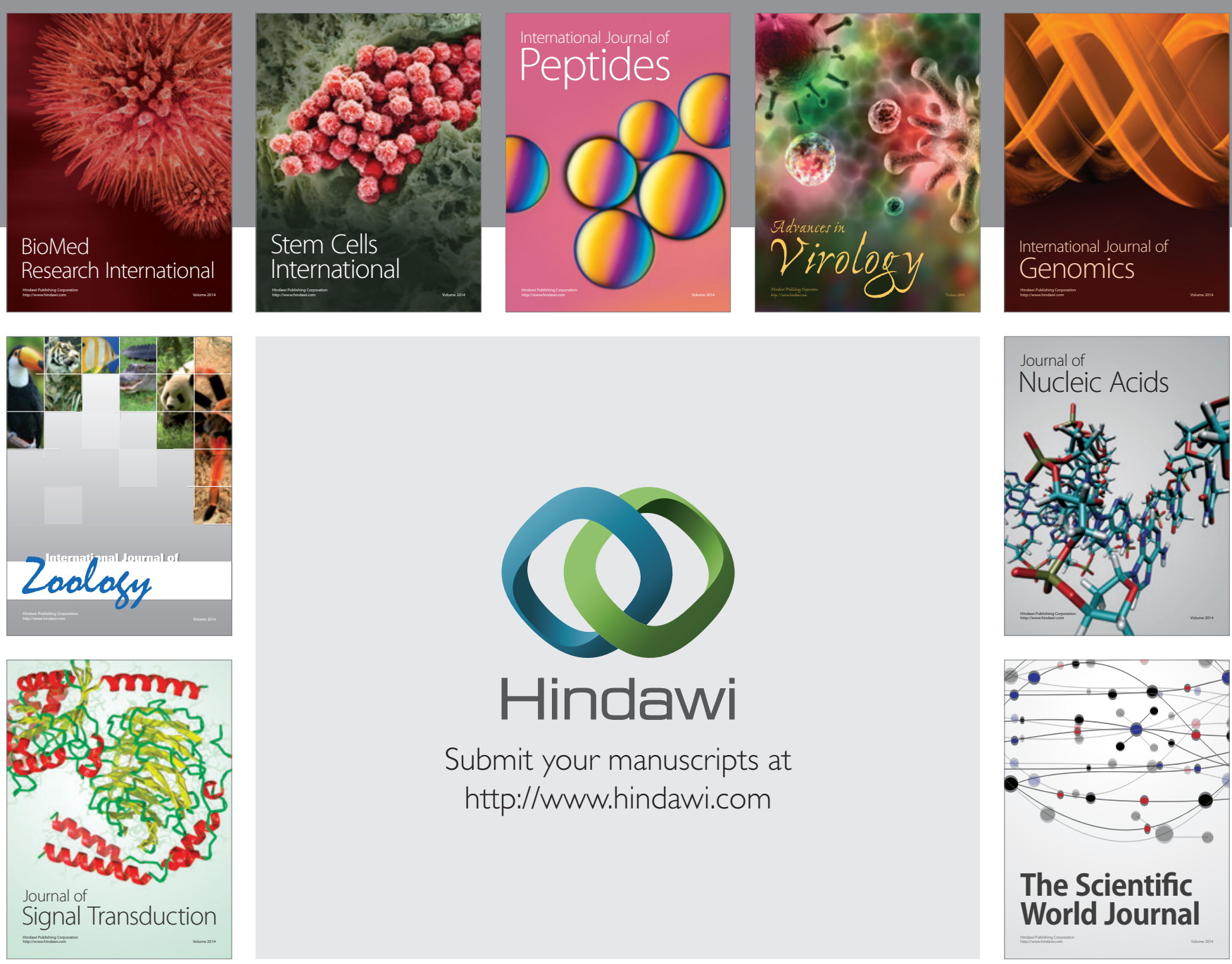

Submit your manuscripts at

http://www.hindawi.com
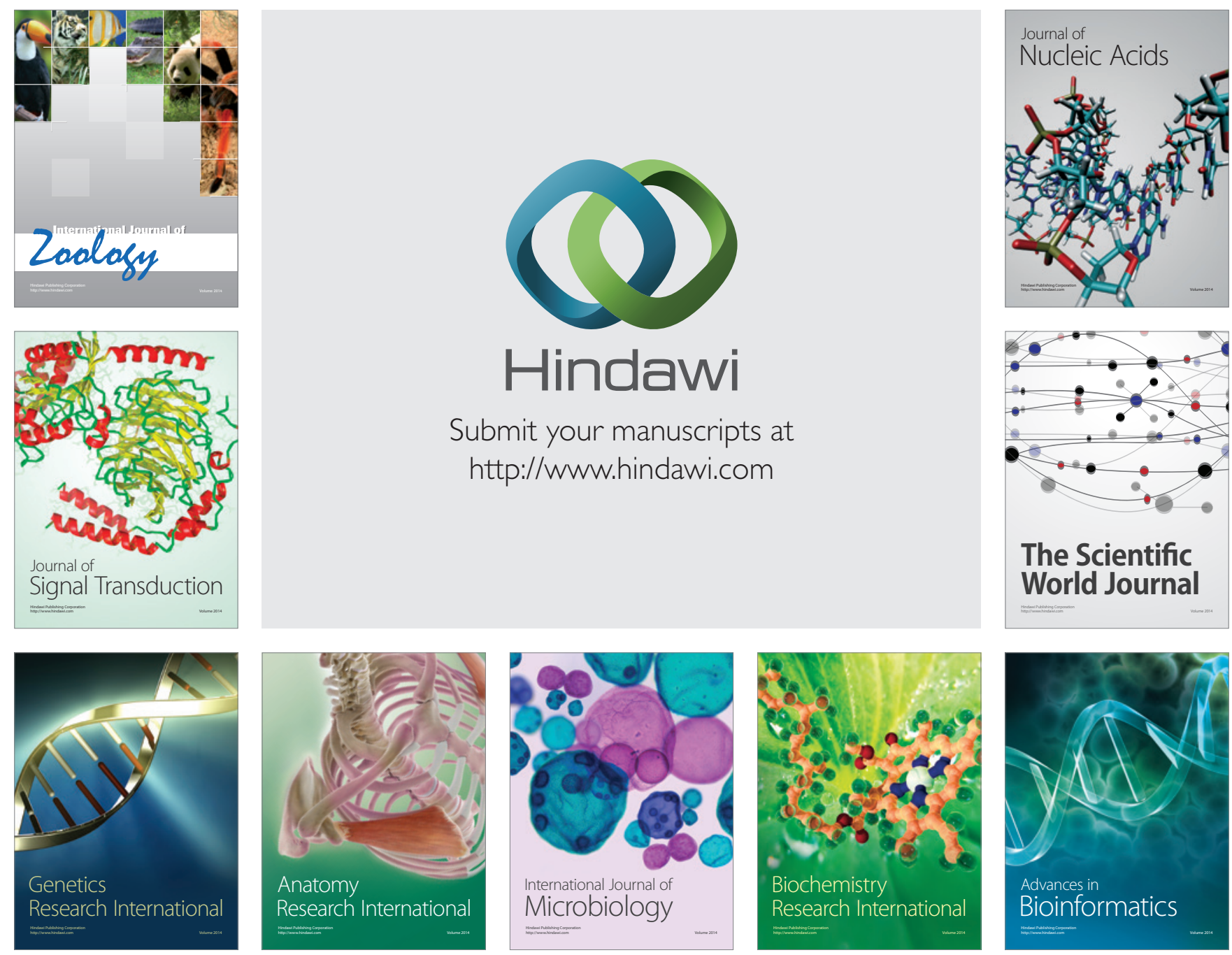

The Scientific World Journal
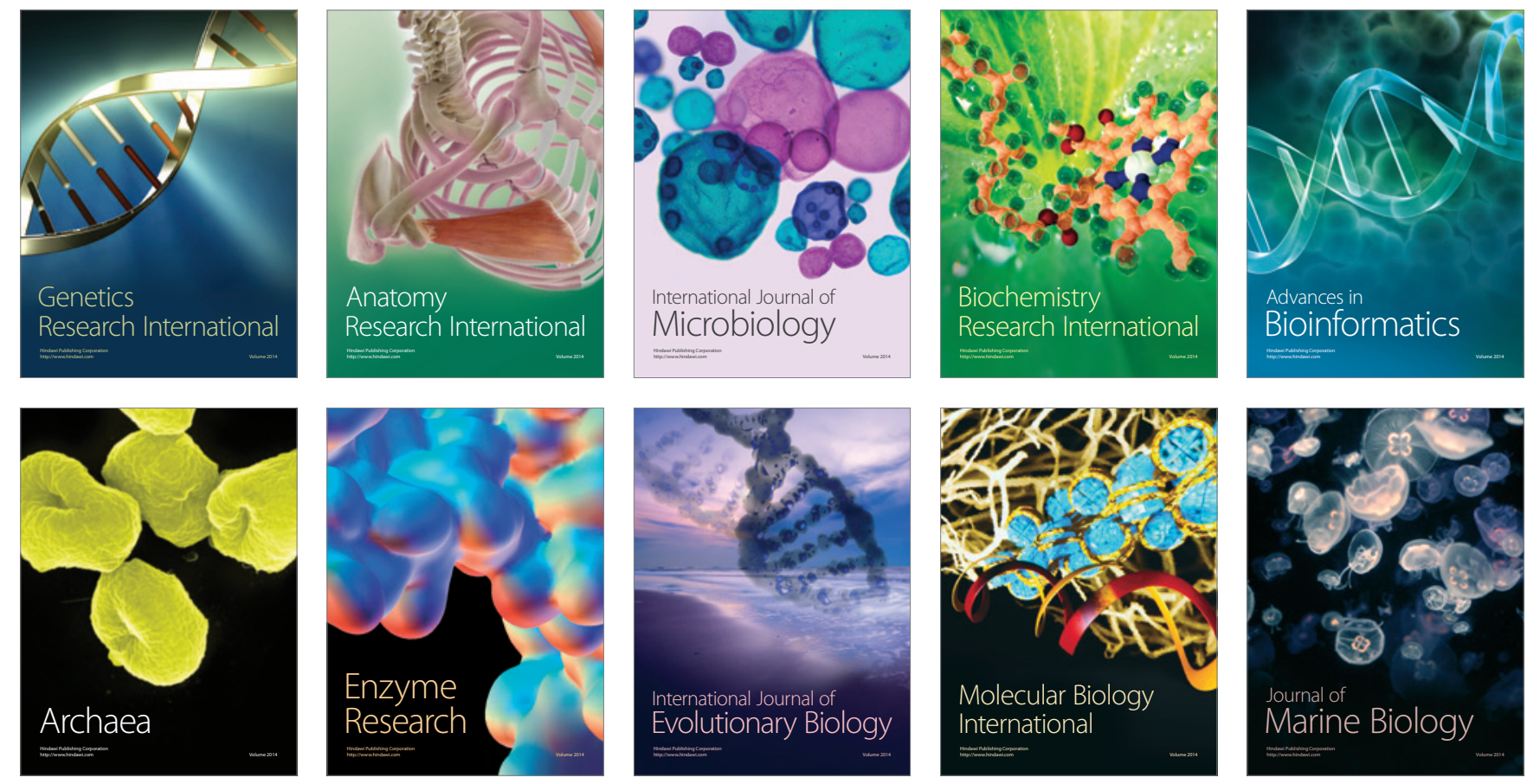